\title{
Pensononowoor
}

2016, vol. 75, 99-112

http://dx.doi.org/10.12657/denbio.075.010

Hanna Kwaśna, Wojciech Szewczyk

\section{Effects of fungi isolated from Quercus robur roots on growth of oak seedlings}

\begin{abstract}
Effects of 62 isolates (of 41 taxa) of fungi on growth of 1-year-old oak (Quercus robur) seedlings were studied in an inoculation experiment. The fungi were isolated from roots of 80-96-year-old Q. robur that had been subjected to periodic flooding and had symptoms of oak decline. The fungal genera included Alternaria, Aspergillus, Calonectria, Chaetomium, Cladosporium, Clonostachys, Corynespora, Cylindrocarpon, Dicyma, Geotrichum, Ilyonectria, Isaria, Metarhizium, Oidiodendron, Ophiostoma, Pezicula, Phialocephala, Phialophora, Pyrenochaeta, Sporendocladia, Sporothrix, Thelonectria, Trichoderma and Trimmatostroma. Mycelial colonies of fungi growing in potato-dextrose broth were used for soil inoculation. Plant growth was assessed 2 years after inoculation, when the plants were 3 years old. Stem lengths, and dry weights of stems, roots and leaves were measured. Stem growth was inhibited by 31 isolates $(50 \%)$ and root growth by 12 isolates (19\%). Stem growth was stimulated by two isolates $(3 \%)$ and root growth by 17 isolates $(27 \%)$. The overall ratio of inhibitors to stimulants was 2.1. The proportion of taxa that inhibited stem growth was 16 times greater than that which promoted stem growth. The proportion of taxa that promoted root growth was only 1.5 times greater than that which inhibited root growth. The structure of the fungal communities in periodically flooded oak forests suggests that they are more likely to inhibit than to promote vigour in oaks.
\end{abstract}

Keywords: growth inhibition, oak fungal root endophytes, oak seedlings

Addresses: H. Kwaśna, Poznań University of Life Sciences, Department of Forest Pathology, Wojska Polskiego 71c, 60-625 Poznań, Poland, e-mail: kwasna@up.poznan.pl W. Szewczyk, Poznań University of Life Sciences, Department of Forest Pathology, Wojska Polskiego 71c, 60-625 Poznań, Poland, e-mail: wszew@up.poznan.pl

\section{Introduction}

Fungal colonization was detected in $94 \%$ of 1296 root fragments of Quercus robur L., the dominant tree in an area of forest displaying symptoms of oak decline in Wołów Forest District in Poland (Kwaśna et al., 2015). The fungal isolates represented 126 species, including four species of Zygomycota, 117 species of Ascomycota and five species of Basidiomycota. The most common and frequent eudominants (with colonization frequency $\geq 10 \%$ ) were Aspergillus spp., Cosmospora sp., Ilyonectria destructans, Pezicula radici- cola, Pyrenochaeta cava and six species of Trichoderma. Structural roots were usually colonized by more species than fine roots. The number of species reported in that research (Kwaśna et al., 2015) corresponds well with another study, in which 119 fungal taxa were identified from living roots of $Q$. petraea and $Q$. robur (Halmschlager and Kowalski, 2004).

The majority of species detected previously (Kwaśna et al., 2015) in Q. robur roots met the requirements of Class $2 \mathrm{NC}$-endophytes (i.e. species within Ascomycota or Basidiomycota which occur in above- and below-ground plant tissues) (Rodriguez 
et al., 2009 a, b). Pezicula radicicola and Phialocephala fortinii met the requirements of Class 4 NC-endophytes (i.e. with darkly melanized septa, conidial or sterile, and restricted to plant roots).

An endophyte is an endosymbiont (bacterium or fungus) that lives within a plant for at least part of its life without causing apparent disease (Carroll, 1986; Clay \& Schardl, 2002). The frequency of endophytes and their high genetic diversity suggest that they are important components of many ecosystems (Mandyam et al., 2012). They may assist in phytostimulation (by production of hormones, i.e. auxins and cytokinins, which stimulate the growth of plants and of mycorrhizal fungi and promote symbiosis between plant and mycorrhizal fungi), biofertilization (by increasing the accessibility or supply of major nutrients, mainly nitrogen and phosphorus), water uptake and biocontrol (by protection from phytopathogens and abiotic stresses) (Scervino et al., 2009; Upson et al., 2009; Hanada et al., 2010; Newsham, 2011). They may help in adaptation to habitats and induction of host resistance (Sieber, 2002; Rodriguez et al., 2004, 2005; Schulz \& Boyle, 2005; Rodriguez \& Redman, 2008).

There are also reports that point out the pathogenic role of endophytes for different hosts, growing conditions and fungal isolates (literature summarized in Grünig et al., 2008). Growth response in tree seedlings may vary from negative to positive (Wilcox \& Wang, 1987; Jumpponen \& Trappe, 1998). Recent studies have more often reported neutral or parasitic effects, manifested by reductions in hostplant growth increments (Tellenbach et al., 2011; Reininger \& Sieber, 2012).

Many plant-fungus interactions have still not been determined (Faeth, 2002, 2009). Since only limited information on plant-fungus relationships in the field is available, the aim of this study was to learn more about the possible function and role of fungi (including NC-endophytes) from oak roots in oak seedlings, and assess possible implications for their involvement in oak decline. The 62 isolates tested were mostly genotypically well-defined ascomycetous fungi originating from the same host, $Q$. robur (Kwaśna et al., 2015). Their effects on growth of $Q$. robur seedlings were determined under controlled environmental conditions.

\section{Materials and methods}

\section{Fungi}

Sixty-two isolates of 41 taxa of fungi were collected from fine $(0.1-0.5 \mathrm{~cm}$ diam.) and structural (0.6$2.0 \mathrm{~cm}$ diam.) roots of 80-96-year-old Q. robur subjected to periodic flooding and with symptoms of oak decline in Wołów Forest District, Poland $\left(51,329^{\circ} \mathrm{N}\right.$, $16,629^{\circ} \mathrm{E}$ ) in 2011 (Kwaśna et al., 2015).

\section{Fungal inoculation and assessment of test plants}

The effects of 62 fungal isolates of 41 taxa on growth of oak seedlings were evaluated in inoculation tests. Inoculum was produced from potato-dextrose broth cultures. Three discs of each test fungus, $5 \mathrm{~mm}$ diameter, were added to $100 \mathrm{ml}$ broth in a 250$\mathrm{ml}$ Erlenmeyer flask. After 30 days of incubation, the pure culture (mycelial colony that developed on the broth surface) and the broth itself, were added and mixed into sandy forest soil ( $\mathrm{pH}$ 6.9; sterilized twice in superheated steam at $180-200^{\circ} \mathrm{C}$, with a 24 -h interval, amended with moderate amount of fertilizer solution) which was then put into $30-\mathrm{cm}$-diameter pots. The soil had $2.8 \%$ humus content, $5.0 \mathrm{mg} 100$ $\mathrm{g}^{-1}$ extractable nitrogen $\left(\mathrm{NO}_{3}{ }^{-}+\mathrm{NH}_{4}{ }^{+}\right), 10.0 \mathrm{mg} 100$

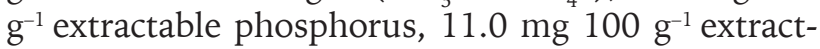
able potassium and $4.0 \mathrm{mg} 100 \mathrm{~g} \mathrm{~g}^{-1}$ extractable magnesium.

At the same time, four 1-year-old $Q$. robur seedlings (16-22 cm high, $0.5-1.0 \mathrm{~cm}$ diameter at the root collar), grown containerized in a mixture of $75 \%$ peat and $25 \%$ perlite, were planted in each of four pots of each treatment. In the control treatment, only $100 \mathrm{ml}$ of sterile liquid broth was added and mixed with the soil. The soil water content was increased weekly, stepwise from $50 \%$ to $70 \%$ of the maximum water capacity, during the test. Pots were weighed twice a week and soil moisture was adjusted by adding water to the pots. Because of the range of sizes of the seedlings, three control variants were included: 'large control' with large plants, 20-22 cm high; 'medium control' with medium plants, $18-20 \mathrm{~cm}$ high; 'small control' with small plants, $16-18 \mathrm{~cm}$ high.

Plants were grown in a greenhouse using artificial light of $280 \mu \mathrm{E} \mathrm{m}^{-2} \mathrm{~s}^{-1}$ for $14 \mathrm{~h}$ per day. A constant temperature of $24^{\circ} \mathrm{C}$ day and night was chosen to guarantee optimal growth of plants and fungi. Relative humidity was adjusted to $70-80 \%$.

The plants were monitored for above-ground symptom development during the incubation period. Plants occasionally became infected naturally with Erysiphe alphitoides (Griffon \& Maubl.) U. Braun $\&$ S. Takam. and spraying with a fungicide was necessary. The fungicide bupirimate (Nimrod 250 EC, applied at $0.1 \%$ concentration at the manufacturer's recommended dose) was sprayed on the seedlings three times at one week intervals (first spray on June 28th).

Plant growth was determined at the end of the experiment in September 2014, 2 years after inoculation, when the plants were 3 years old. The plants 
were removed from the pots, the leaves were separated, and the root system was cut off and gently washed. Stems, roots and leaves were oven-dried at $65^{\circ} \mathrm{C}$ for $48 \mathrm{~h}$ and stem length and dry weights of stems, roots and leaves of each plant were determined. Mean values were calculated.

Re-isolation of fungi from roots was attempted after plant harvest. Two 5-cm-long root pieces from each plant were surface-sterilized by shaking for $5 \mathrm{~s}$ in $70 \%$ ethanol and $15 \mathrm{~min}$ in $10 \% \mathrm{H}_{2} \mathrm{O}_{2}$, and subsequently rinsed three times for $3 \mathrm{~min}$ in sterile distilled water, dried between sterile sheets of filter paper, cut into 2-4-mm-long sections and placed in Petri dishes on potato dextrose agar (PDA; Difco PDA $39 \mathrm{~g} \mathrm{l}^{-1}, \mathrm{pH}$ 5.5) amended with streptomycin $\left(0.06 \mathrm{~g} \mathrm{l}^{-1}\right)$ and synthetic nutrient agar (SNA; KH${ }_{2} \mathrm{PO}_{4} 1 \mathrm{~g} \mathrm{l}^{-1}, \mathrm{KNO}_{3} 1 \mathrm{~g} \mathrm{l}^{-1}, \mathrm{MgSO}_{4} 7 \mathrm{H}_{2} \mathrm{O}_{0.5 \mathrm{~g} \mathrm{l}^{-1}, \mathrm{KCl}}$ $0.5 \mathrm{~g} \mathrm{l}^{-1}$, glucose $0.2 \mathrm{~g} \mathrm{l}^{-1}$, sucrose $0.2 \mathrm{~g} \mathrm{l}^{-1}$, agar $20 \mathrm{~g}$ $\left.\mathrm{l}^{-1}\right)$. After incubation for $15-30$ days at $25^{\circ} \mathrm{C}$, cultures were identified on the basis of their morphology and sporulation. The percentage of positive re-isolation was recorded.

The effects of the fungi on stem length and on dry weights of stems, roots and leaves were analysed by one-way analysis of variance (ANOVA) (GLM, SAS/ STAT $8 \cdot 1)$. Ratios of stem weight effect $(\%)$ : root weight effect (\%) were calculated.

\section{Results}

Aspergillus niger, A. pullulans, Basidiomycota (D 109), C. globosum (D 53), two strains of C. didymum (D 9, D 15 partly), D. biophila (partly), I. destructans (D 23), M. anisopliae, P. bubakii (D 57), P. verrucosa, two strains of $P$. cava (D 6, D 30), S. inflata (D 102), T. citrinoviride, T. polysporum (D 124), T. pubescens (D 115), T. virens (D 131 partly) and dark septate endophyte (D 51) stimulated the growth of oak stems or roots and sometimes also increased leaf biomass (Table 1$)$. The statistically significant $(P<0.05)$ stimulatory effects were $38-202 \%$ of the control.

Alternaria alternata, Armillaria sp., two species of Basidiomycota (D 60, D 125), C. kyotensis, C. candelabrum, C. rosea, Cosmospora sp. (D 24), C. didymum (D 15 partly), D. biophila, G. candidum, I. destructans (D 4, D 12), I. fumosorosea, O. griseum, three isolates of $P$. radicicola, $P$. fortinii, two isolates of $P$. cyclaminis, $P$. cava (D 6), S. bactrospora, four isolates of $S$. inflata (D 47, D 50, D 101, D 102), T. harzianum, T. polysporum (D 69), T. pubescens (D 64), T. virens (D 128, D 129) and Trimmatostroma sp. reduced the length and/or dry weight of oak stems and/or roots. The statistically significant $(P<0.05)$ inhibitory effects were 17 $70 \%$ of the control.

Chaetomium globosum (D 56), C. cladosporioides, C. herbarum, C. citricola, Cosmospora sp. (D 1, D 2), I. de- structans (D 5, D 11), P. cinerescens, P. cava (D 28), S. inflata (D 26, D 33), T. lucida and dark septate endophyte (D 7) did not affect plant growth.

Ratios of stem weight effect (\%): root weight effect $(\%)$ show that there was a greater response (either positive or negative) in stems than in roots to 20 isolates including Armillaria sp., Basidiomycota (D 60), C. kyotensis, C. globosum (D 56), C. candelabrum, C. rosea, Cosmospora sp. (D 24), I. fumosorosea, O. griseum, P. radicicola (D 14), P. cyclaminis (D 16, D 54), S. inflata (D 33, D 47, D 50, D 101), T. harzianum, T. polysporum (D 69), T. virens (D 129) and Trimmatostroma sp. Response to the other 42 isolates (either positive or negative) was greater in roots. Effects on roots increased as ratio of stem weight effect (\%): root weight effect (\%) decreased.

Stem growth was inhibited by 31 isolates $(50 \%)$ and root growth by 12 isolates (19\%). Stem growth was stimulated by two isolates $(3 \%)$ and root growth by 17 isolates $(27 \%)$. The overall ratio of inhibitors to stimulants was 2.1. The proportion of taxa that inhibited stem growth was 16 times greater than that which promoted stem growth. The proportion of taxa that promoted root growth was only 1.5 times greater than that which inhibited root growth.

Forty-three isolates of fungi $(70 \%)$ were successfully re-isolated from roots two years after application. Positive re-isolation ranged from 25 to $100 \%$ for individual isolates. Nineteen isolates (30\%) were not re-isolated (Table 1).

\section{Discussion}

Plant roots are colonized by a variety of microorganisms, including pathogenic, mycorrhizal and endophytic fungi. The role of many fungal root colonizers is still un-known or controversial. Many non-clavicipitaceous (NC) endophytes increase host stem and/or root biomass by mechanisms that involve induction of plant hormones by the host and/ or biosynthesis of plant hormones by the fungi (Tudzynski \& Sharon, 2002; Rodriguez et al., 2009 a, b), modulation of plant growth via nutrient mineralization (Waller et al., 2005; Baltruschat et al., 2008) or earlier expression of age-dependent genes (Waller et al., 2008). A wide set of phytohormones and their signaling networks are involved in increasing root growth and biomass of plants (Liarzi \& Ezra, 2014). They may be regulated epigenetically by the fungal endophyte; in symbiotic plants the resources are preferentially allocated into root growth until root hairs are established, therefore increasing the rate of root expansion (Rodriguez et al., 2009 a).

The present results, as well as those in some other papers (Wilcox \& Wang, 1987; Stoyke \& Currah, 1993; Tellenbach et al., 2011; Mandyam et al., 


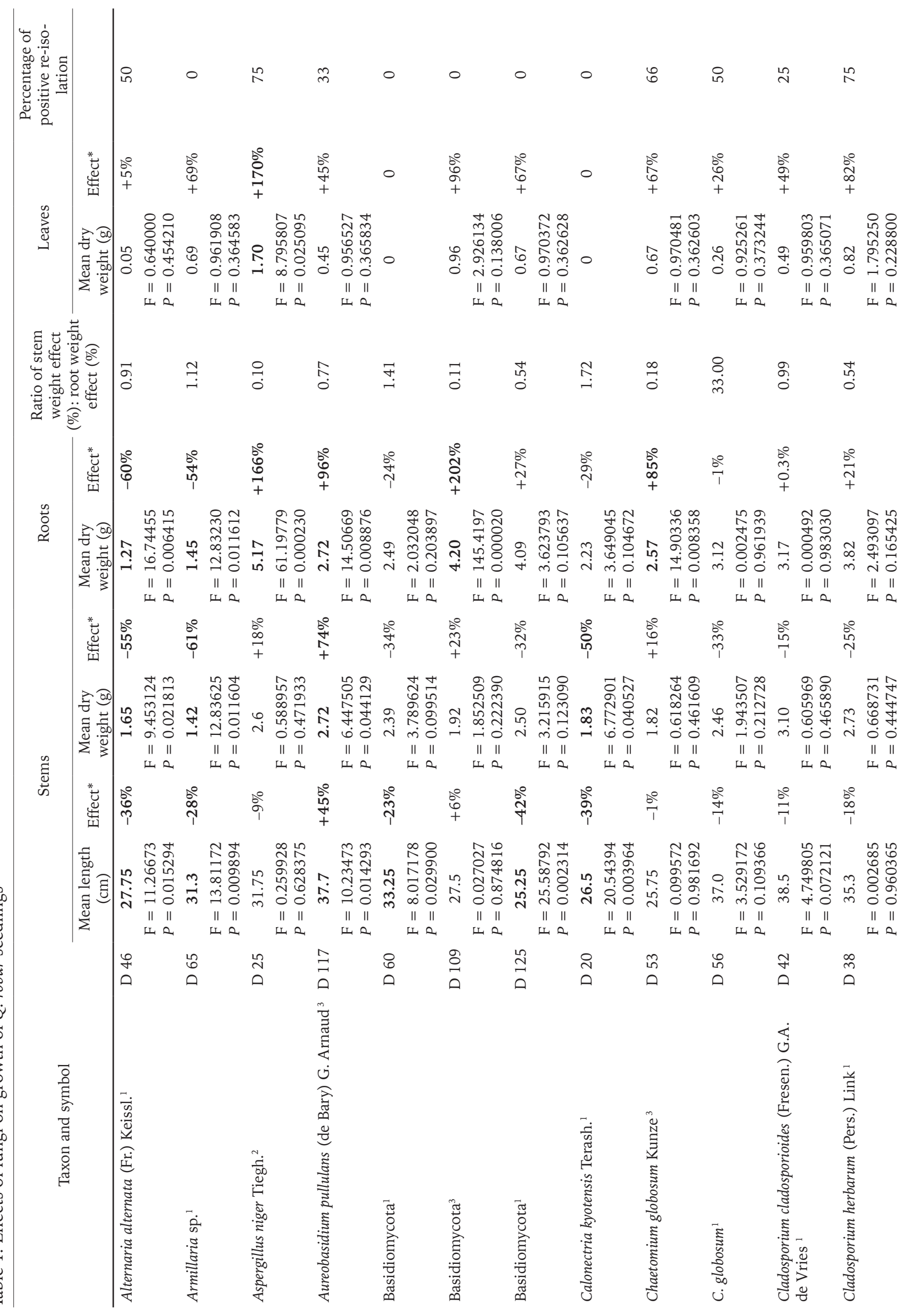




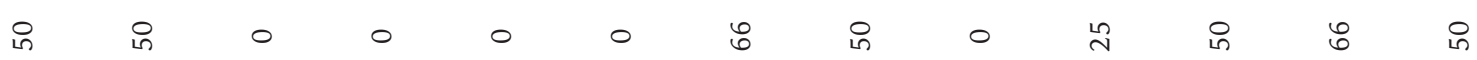

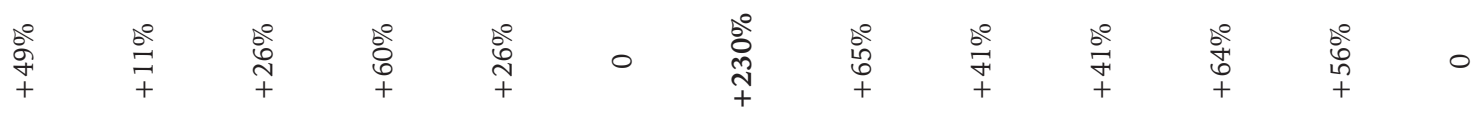

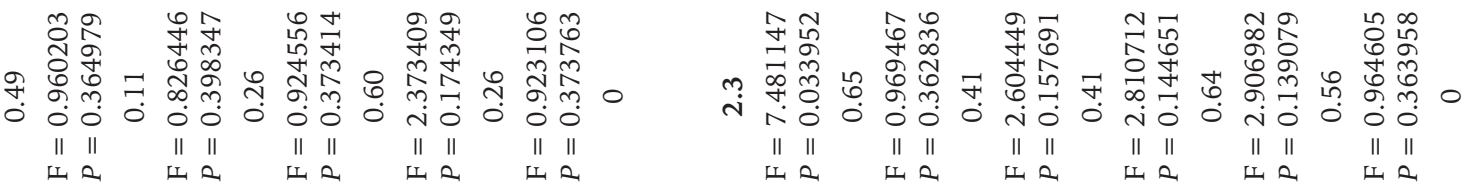

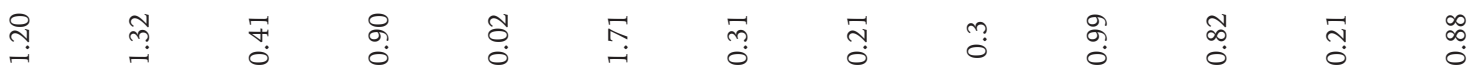

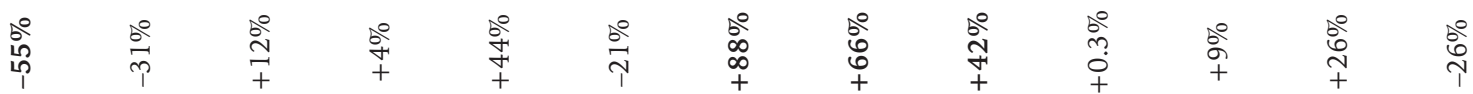

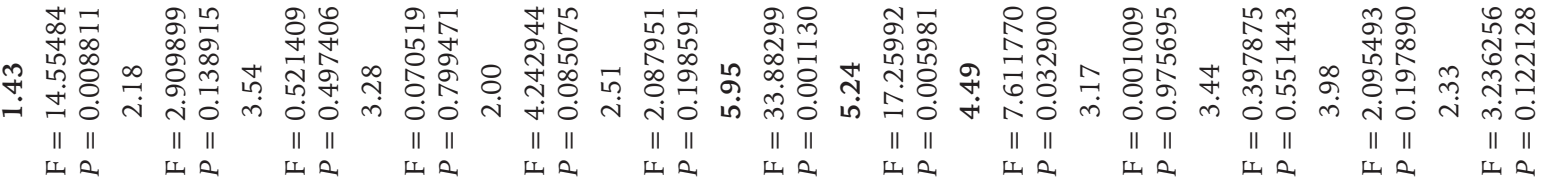

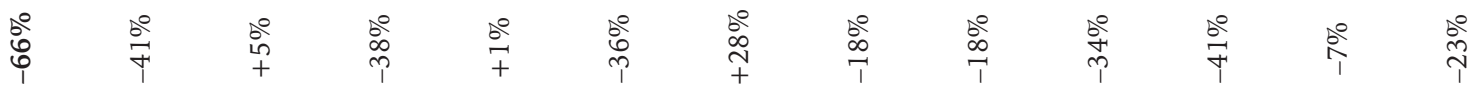

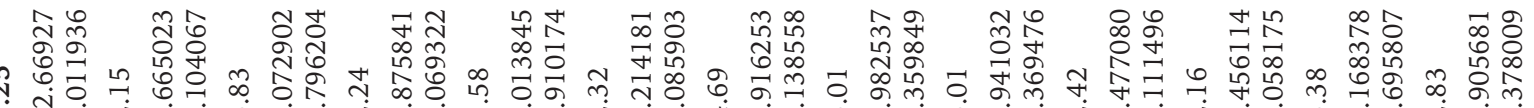
গ广 || || || || || || || || || || || || || $\mid$ || || || || || || || || || ||

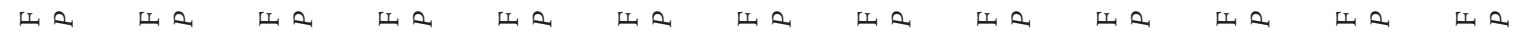

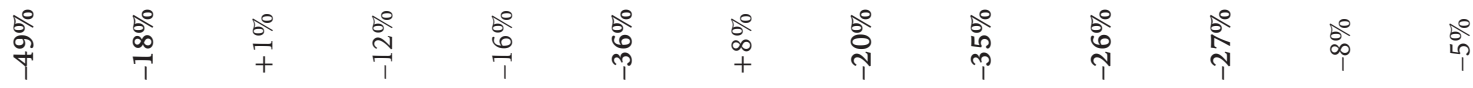

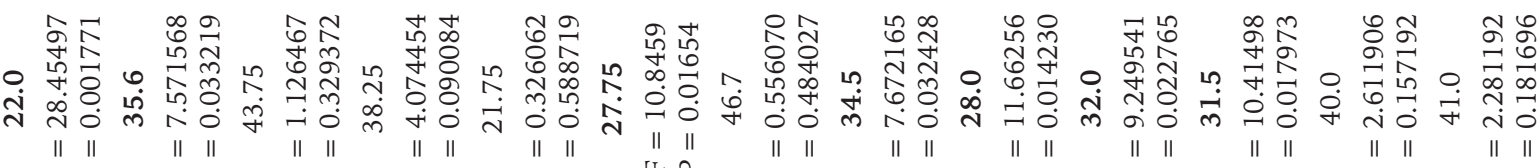

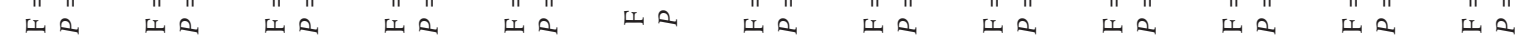

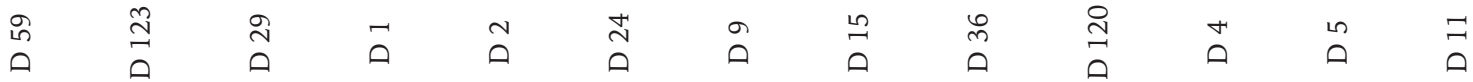

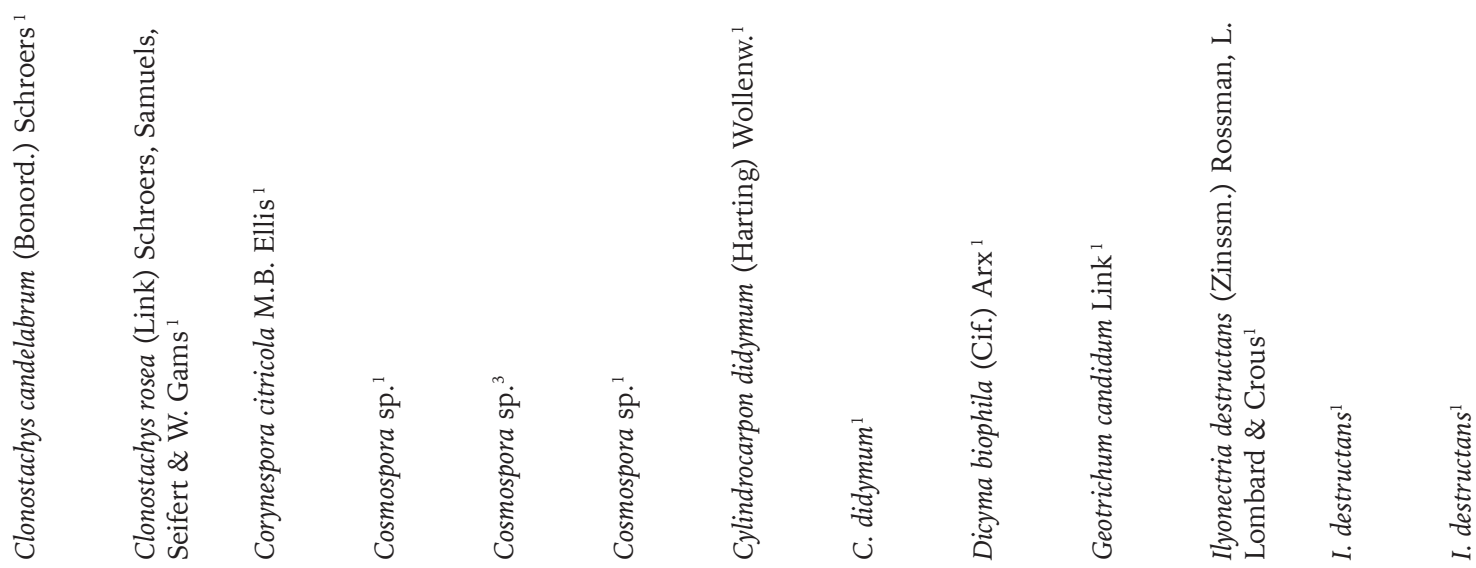




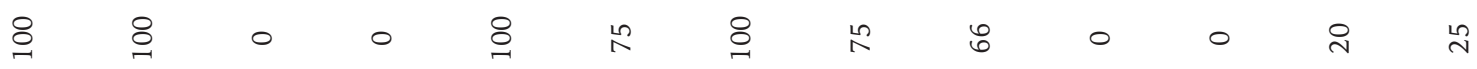

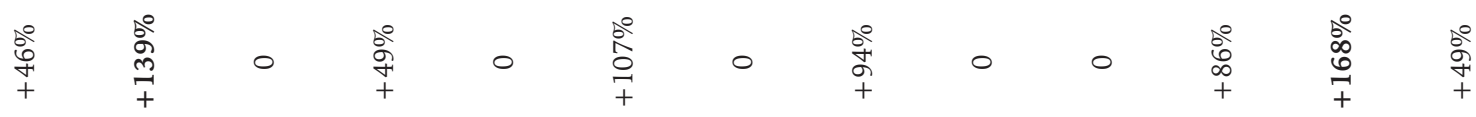

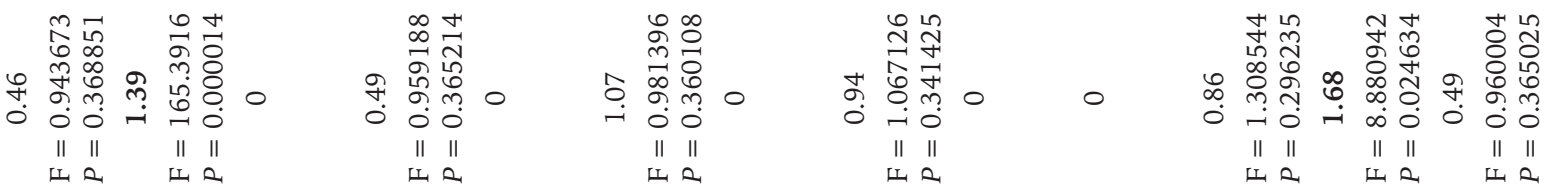

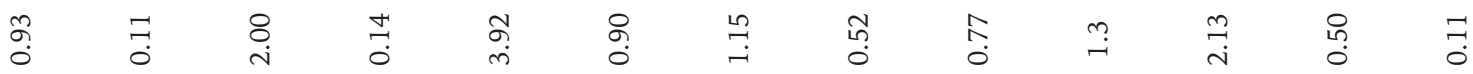

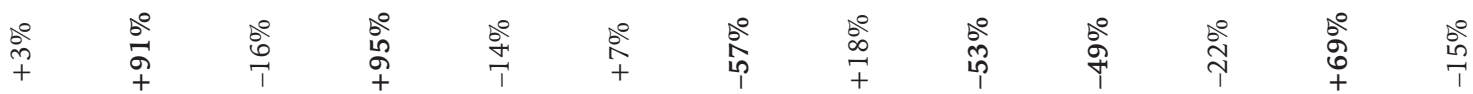

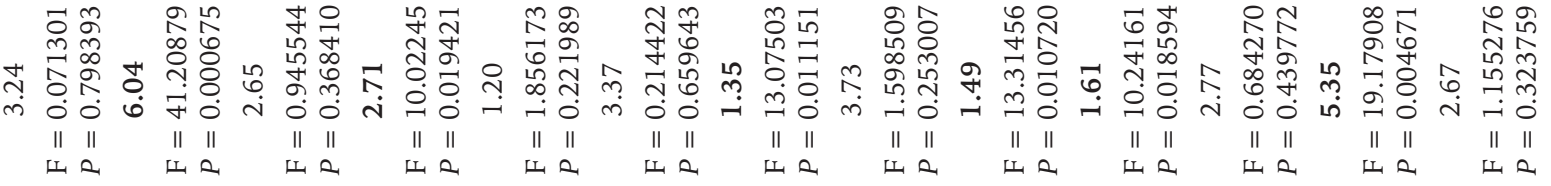

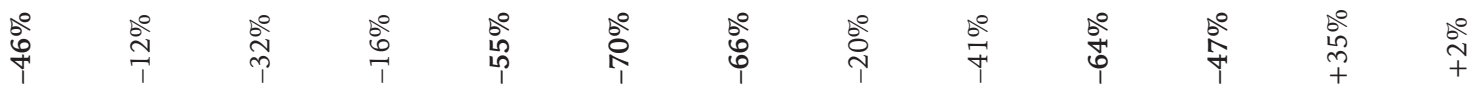

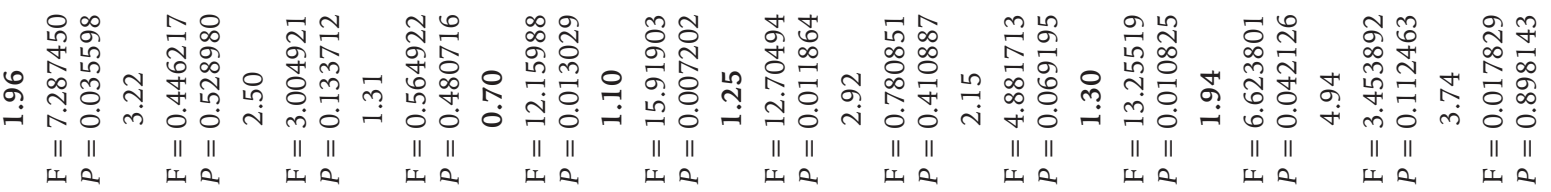
审

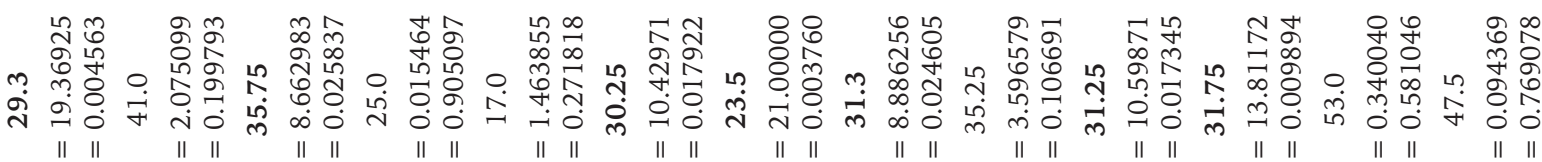

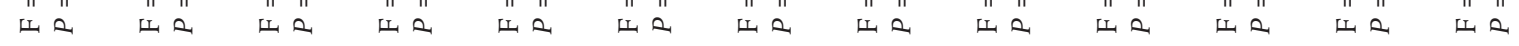

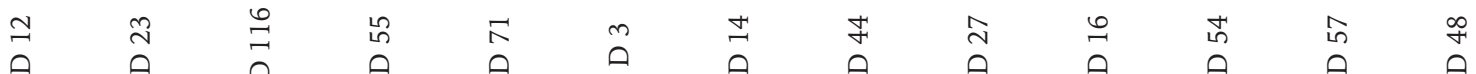

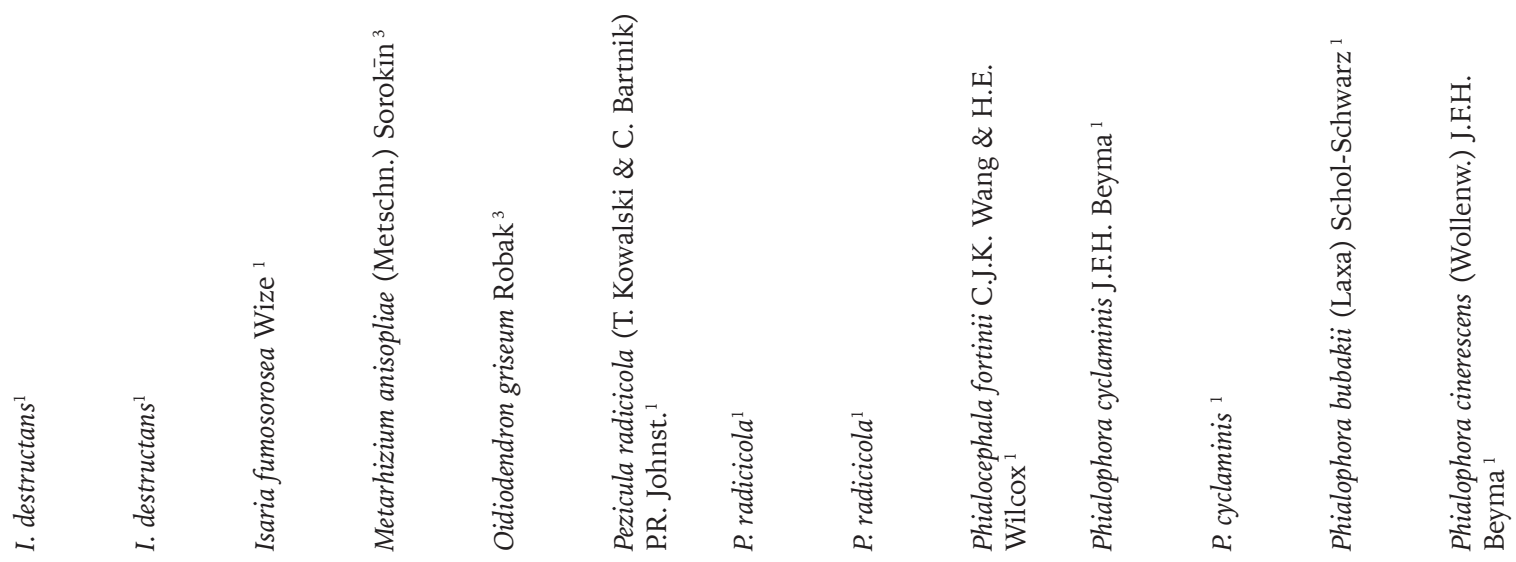




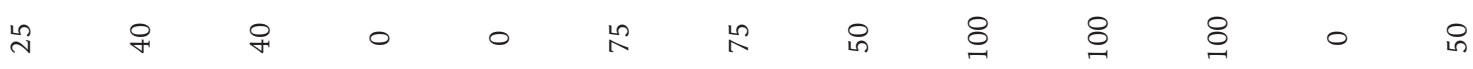

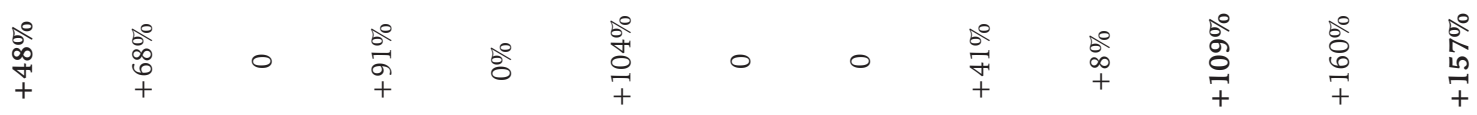

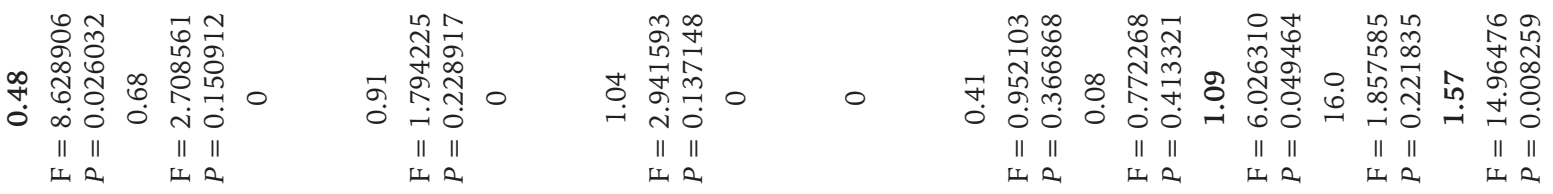

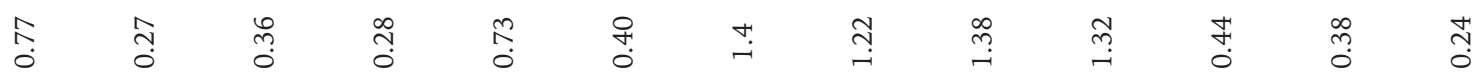

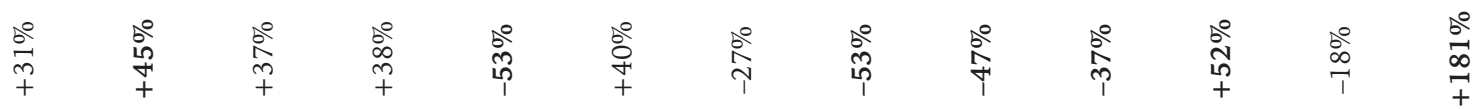

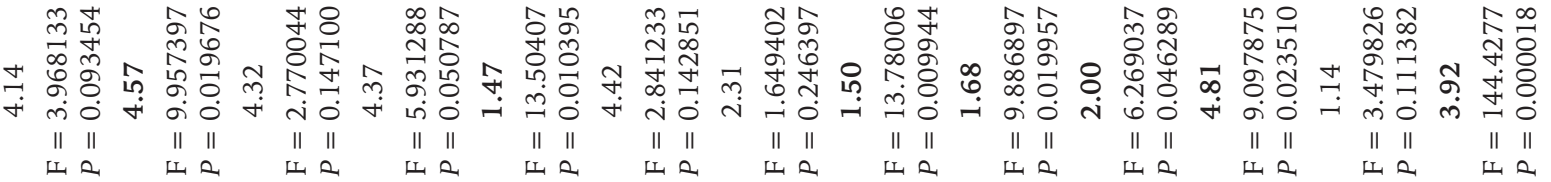

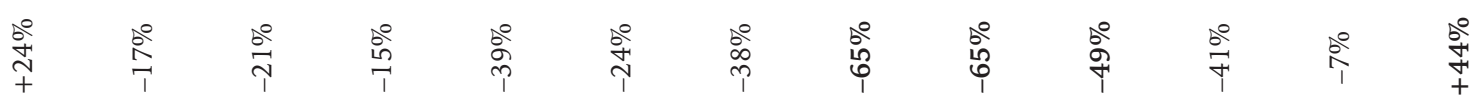

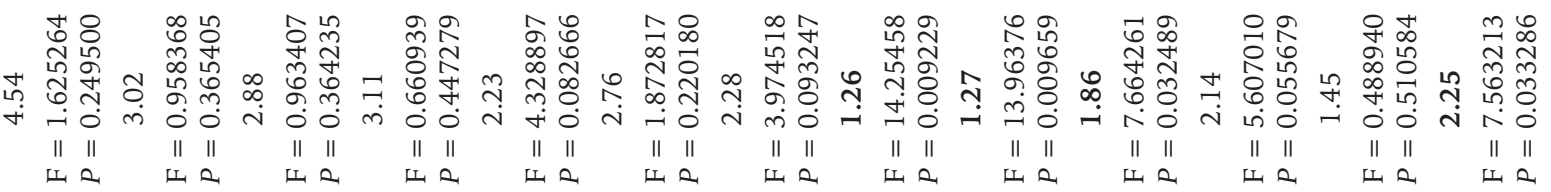
今̊

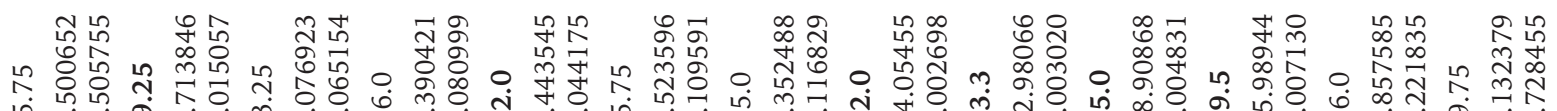

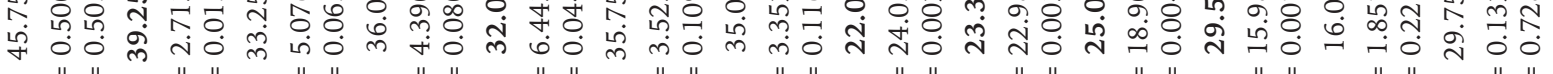
|| || || || || || || || || || || || || || || || || || || || || || || || || ||

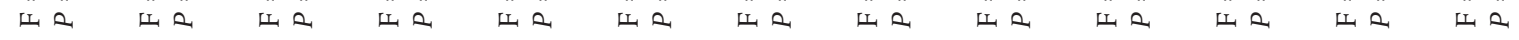

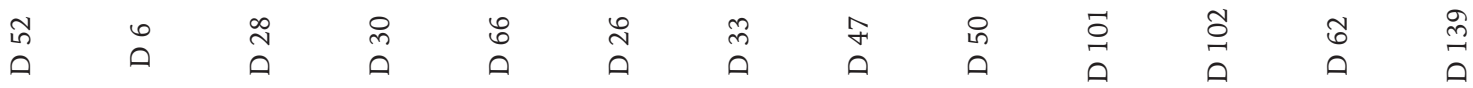

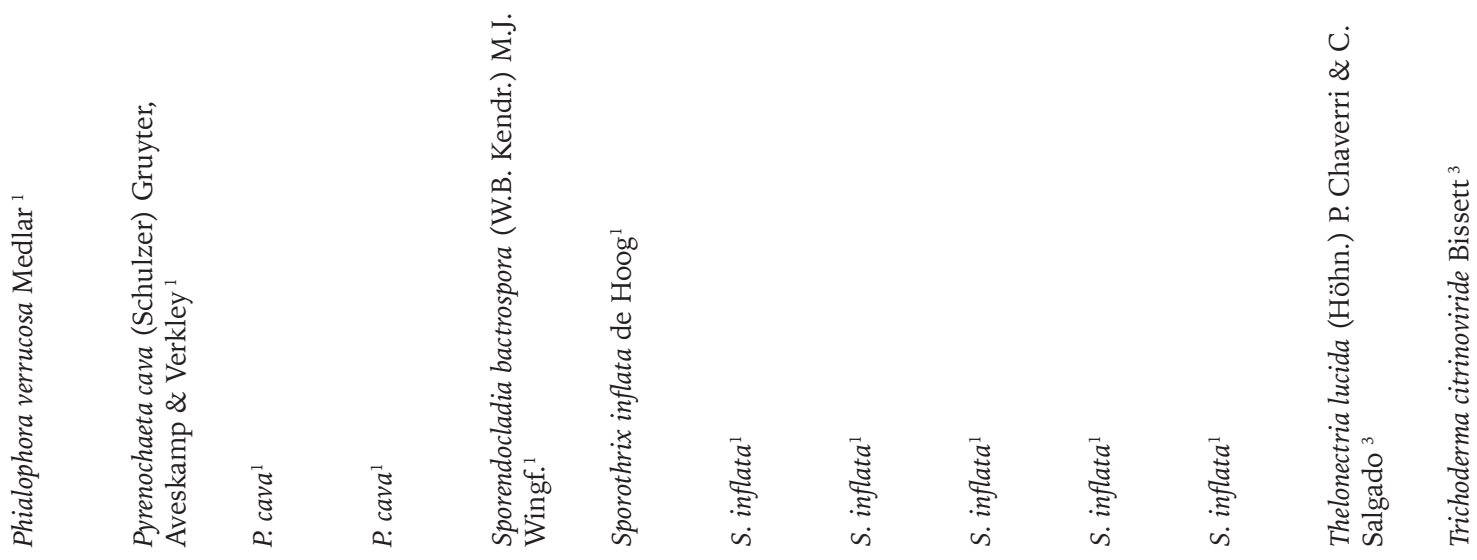




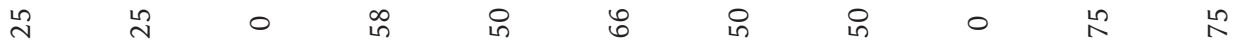

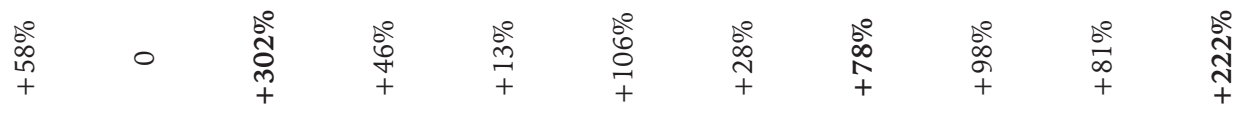

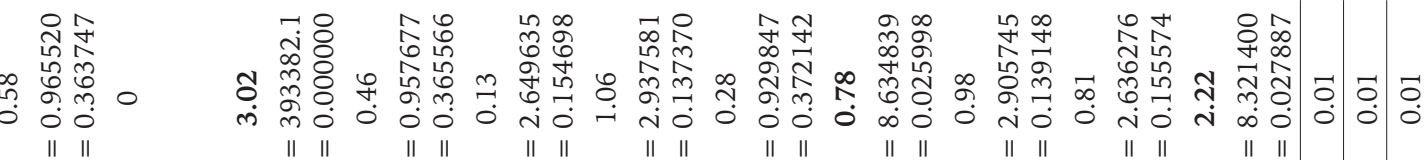

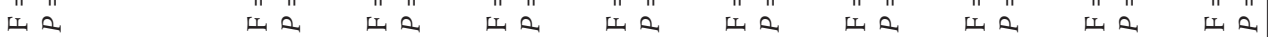

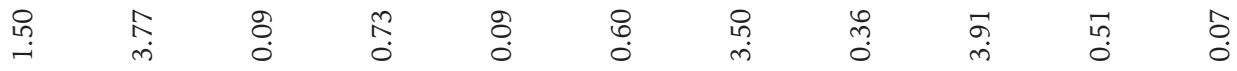

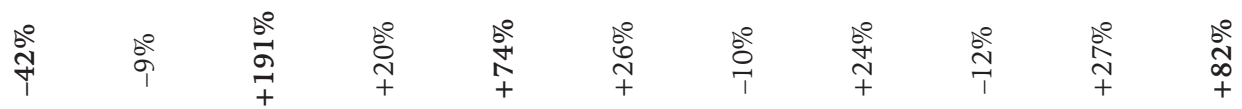

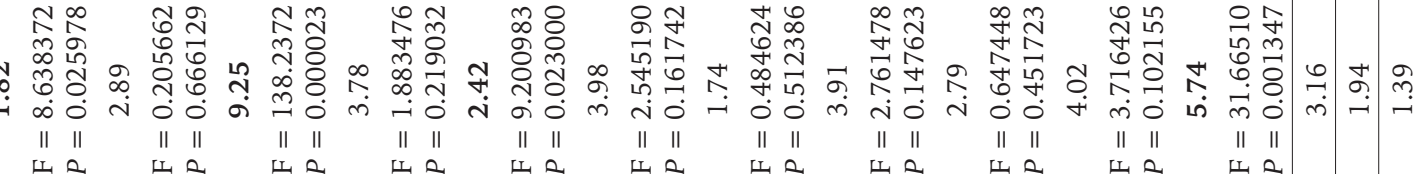
审

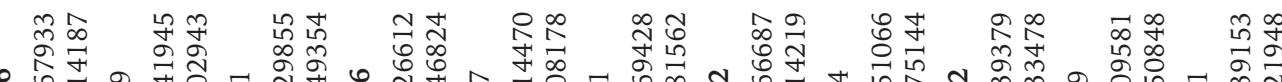

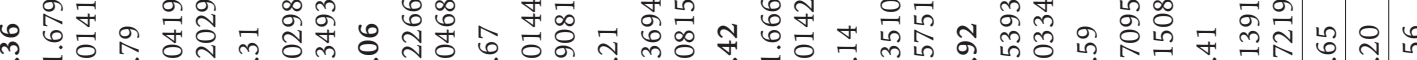

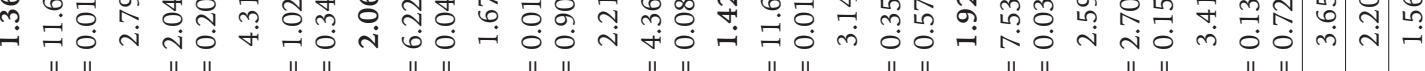

|山

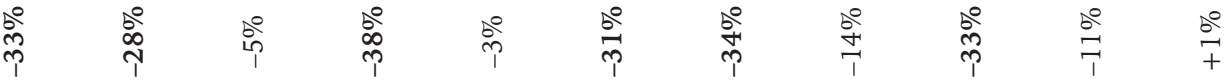

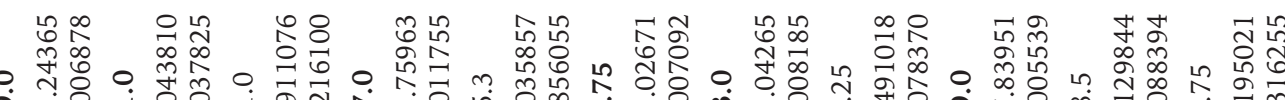

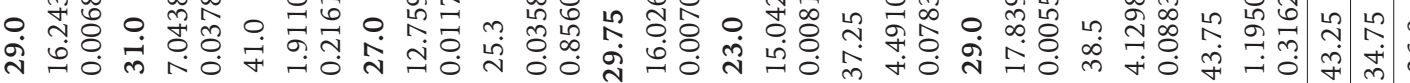

॥| in

山 2 It

II

山 2

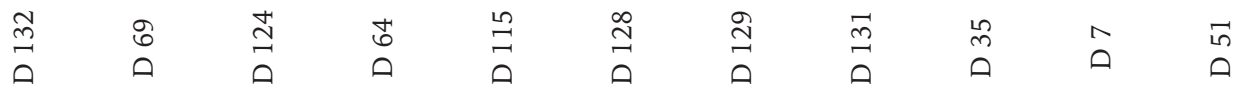
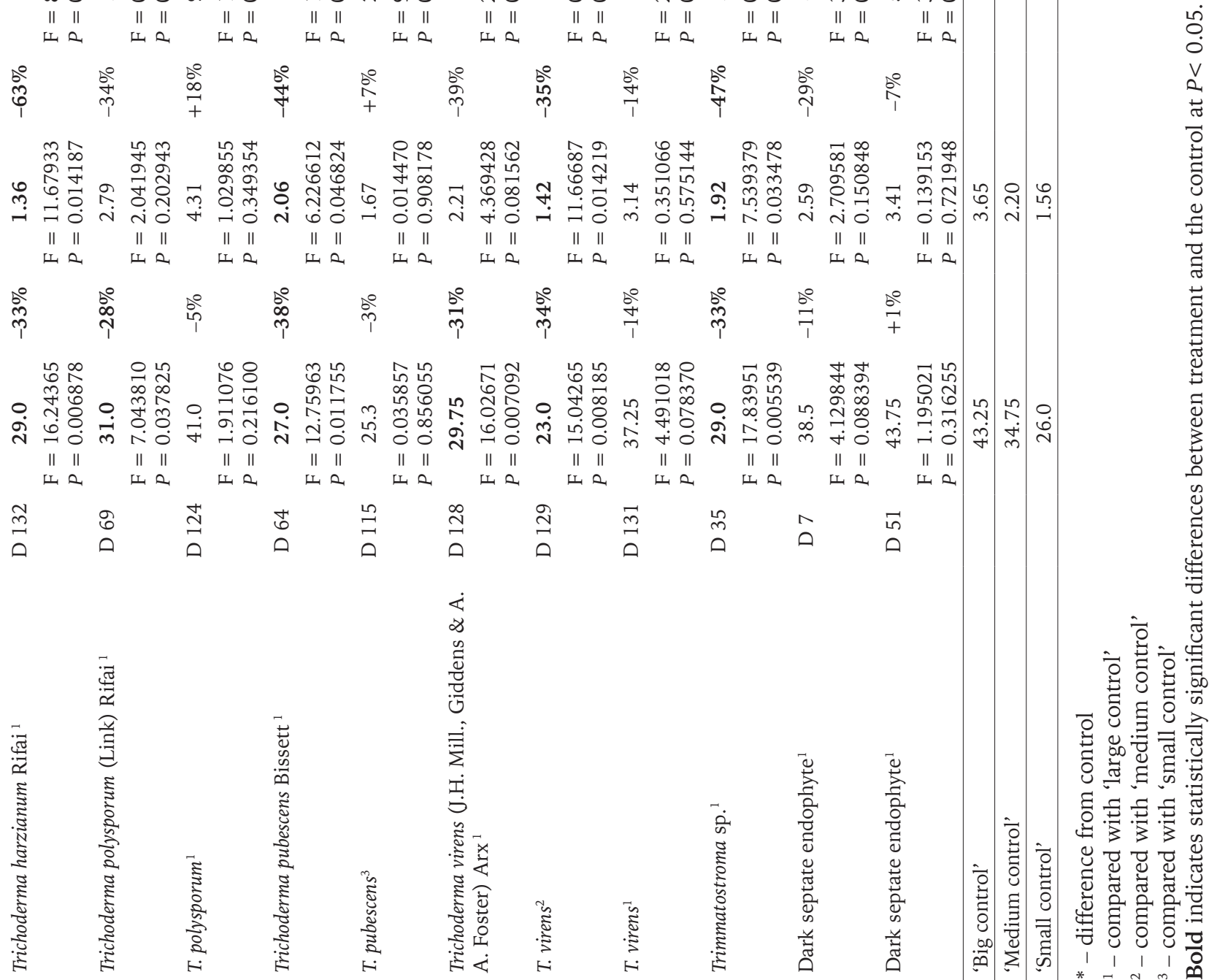
2013), show, however, that most ascomycetous fungi (including a wide range of endophytes) can reduce host-plant growth increments. This agrees also with Mayerhofer et al. (2013) who demonstrated that the overall response of plant biomass to ascomycetous root endophytes is neutral to negative. The total biomass was $18 \%$ less in endophyte inoculated plants, and individually, root biomass, shoot biomass, and nitrogen concentration responses were often neutral. An extensive meta-analysis by Mayerhofer et al. (2013) included data from 34 publications and 21 different factors selected for their potential effects on plant response to root colonizer.

The possible explanation for the present findings as well as for the Mayerhofer et al. (2013) evaluation is that the studies included a wide range of fungi, not only the dark septate endophytes that are usually typical stimulants (Alberton et al., 2010; Newsham, 2011) but also other endophytes that are potential inhibitors.

In the present study, as in reports of Johnson et al. (1997), Sturz \& Nowak (2000) and Larimer et al. (2010), three types of plant-fungus interactions along the mutualism-parasitism continuum were observed. Taxa that stimulated oak growth increments (conferred benefits) seemed to be mutualistic and those that inhibited oak growth seemed to be antagonistic (i.e. parasitic). Some isolates of C. globosum, C. cladosporioides, C. herbarum, C. citricola, Cosmospora sp., I. destructans, $P$. cinerescens, $P$. cava, $S$. inflata and T. lucida as well as some dark septate endophytes seemed to be neutral. Antagonists (i.e. parasites) may slow down plant growth by allocation of resources or penetration of living host cells. They may remain latent until the host's physical status or environmental conditions change and trigger their pathogenicity instantly afterwards (Sinclair \& Cerkauskas, 1997; Saikkonen et al., 1998; Sieber, 2007; Barrett et al., 2009).

The dominant species in $Q$. robur roots in Wołów Forest District was P. radicicola (Kwaśna et al., 2015). The $Q$. robur-P. radicicola interaction observed in the present study was usually parasitic. Other species of Cryptosporiopsis (= anamorphs of Pezicula) may, however, be commensals; they may confer resistance to virulent pathogens in barley and larch (Schulz et al., 1999). The aspen-P. radicicola and larch-Cryptosporiopsis spp. interactions, evaluated on the basis of anatomical contacts and secondary metabolite production, were defined, respectively, as antagonism (Tsuneda et al., 2009) or balanced antagonism that does not result in disease (Schulz et al., 1999).

Two of the five isolates of I. destructans significantly inhibited stem length and weight, and another isolate stimulated root growth. This result was rather unexpected since I. destructans is known to cause root dieback in young and older oaks (Kessler, 1988; Sánchez et al., 2002; Halmschlager \& Kowalski, 2004).
The three isolates of Pyrenochaeta cava (syn. Phoma cava Schulzer) stimulated the growth of roots and two of them stimulated, non-significantly, leaf growth. This is consistent with findings of Newsham (1994) and Macia'-Vicente et al. (2008 a, b) who observed that Phoma fimeti Brunaud, P. glomerata (Corda) Wollenw. \& Hochapfel, P. herbarum Westend, $P$. leveille Boerema \& G.J. Bollen and P. putamina Speg., which are common root endophytes of Mediterranean plants, grasses and natural vegetation, can increase plant growth, confer fitness benefits to plants and reduce symptoms caused by pathogens. They colonize the rhizosphere and often the root cortex, usually asymptomatically, sporulate in the root cells and are passively distributed by the division of host cells.

The host plants' responses to C. globosum, Cosmospora sp., I. destructans, S. inflata, T. pubescens and T. virens in the inoculation test was isolate-dependent. Similarly, a high level of variation among isolates was regularly observed in other studies on mutualists (Munkvold et al,. 2004; Koch et al., 2006) and pathogens (Robin \& Desprez-Loustau, 1998; Wang et al., 2007; Barrett et al., 2009; Rowe \& Kliebenstein, 2010), indicating that it is essential to study many isolates to fully recognize variation in host-fungus relationships. Diverse effects on the plant, varying from parasitic to symbiotic, may result from: (i) accumulation and concentration of hormones and the intensity of plant reactions (Contreras-Cornejo et al., 2009) or (ii) the cost-benefit ratio between the host's carbon investment to the maintenance of symbiosis and the benefit derived from it Johnson et al., 1997; Schwartz \& Hoeksema, 1998; Mandyam \& Jumpponen, 2005; Hoeksema et al., 2010).

The present study, with minimal environmental variability, shows the simultaneous contribution of fungal and host genotypes. A few other studies have documented host and/or fungal genotypic effects (Munkvold et al., 2004; Koch et al., 2006; Picule11 et al., 2008; Karst et al., 2009; Tellenbach et al., 2011). Some emphasize the host (Redman et al., 2001; Faeth \& Sullivan, 2003), others the fungal (Freeman \& Rodriguez, 1993; Tanaka et al., 2006) genotype as the governing agent.

We included only one isolate of Phialocephala fortinii in the inoculation test. This fungus was rare in the roots of the 80-96-year-old Q. robur subjected to periodic flooding; it occurred only in two sites, with frequency 0.9-1.8\% (Kwaśna et al., 2015). Generally, however, $P$. fortinii s. 1 . is commonly isolated from a wide variety of woody plants across North America and Europe (Jumpponen \& Trappe, 1998; Grünig et al., 2008). In the inoculation test the fungus inhibited the growth of seedlings, which tended to have smaller biomass than the controls. This is in accordance with studies of Melin (1922), Richard et al. 
(1971), Richard \& Fortin (1974), Wilcox \& Wang (1987), Tellenbach et al. (2011) and Reininger et al. (2012). Richard and Fortin (1974) suggested that, despite its common occurrence in healthy roots, it may be a mild pathogen. The effect may be strain-dependent since some studies showed negative (Tellenbach et al., 2011; Reininger et al., 2012) and others positive growth responses to P. fortinii (Jumpponen et al., 1998; Ruotsalainen \& Kytöviita, 2004; Newsham, 2011).

The overall ratio of inhibitors to stimulants of the oak seedlings' growth was 2.1. This value was determined by the spectrum of species and number of isolates included in the inoculation tests. Because this spectrum reflected the fungal community in oak roots in Wołów Forest District (Kwaśna et al., 2015), an overall inhibitory effect of the fungal community may be expected in roots of oak in the particular conditions of Wołów Forest District.

Since the fungi tested had been isolated from oak roots, a smaller ratio of inhibitors to stimulants (even <1) was expected. Klironomos (2003) reported that the benefits resulting from root colonization may be related to host specificity of the colonizer. Mayerhofer et al. (2013) reported a positive response (up to $88 \%$ increase of root biomass) resulting from inoculation with a fungus originating from the same plant species or a negative response from inoculation with a fungus from a different plant species. This seems not to be confirmed by the present study.

The interactions observed resulted from host-fungus relationships in single-strain treatments. Co-inoculations with multiple strains of the same species or multiple species may result in different life strategies and plant-growth-promoting characteristics. Tellenbach et al. (2011) found that, even when only two strains were involved in dual-strain treatment in vitro, they had neutralizing effects on each other. Experimental conditions influence the plant-fungus relationship. Differences in methods applied and experimental conditions provided in different studies undoubtedly contribute to the high levels of variability in plant responses reported for individual fungi. In the conditions of our inoculation test, plant response was observed more often on roots than on stems. Increase in root thickness was often inhibited as roots became fibrous and development of more lateral roots was observed. Most plants inoculated with fungi developed more leaves than those in the control. An overall increase of the aerial biomass and development of inflorescence resulting from the plant-fungus interaction has also been observed (Das et al., 2012). Increased leaf area, higher photosynthetic potential and chlorophyll levels result in increased carbon assimilation, which, in symbiotic plants, is the basis for faster development and higher biomass production.
In nature, fungi never act in sterile conditions. In the inoculation tests, containerized seedlings, with non-sterile roots, were planted into soil in order to create the most natural conditions. Thus, primary colonizers (present before inoculation) of seedling roots used in the experiment would have been the same as those on seedlings used for planting in the forest. We also did not want to eliminate the impact of rhizosphere microorganisms by sterilization. Rhizosphere microbiota affect plants by modifying the soil both chemically and physically in and around the roots. This can be beneficial to the plant (by pathogen suppression, formation of an effective rooting area, release of nutrients and plant growth regulators, altering enzyme production and activity, or preventing dehydration and desiccation) or detrimental (by competition for nutrients) (Ridge \& Rovira, 1971; Sylwia et al., 2005). However, in avoiding the consequences of habitat sterility, it was not possible to avoid the consequences of non-sterility, which may include interactions among soil/rhizosphere microbiota and the fungi being tested.

The re-isolation of fungi from roots two years after inoculation was mostly successful. The results were, however, negative for $30 \%$ of taxa, possibly because of the non-sterile conditions used. Re-isolation has also been unsuccessful in some previous studies (Anderson \& Anderson, 1964; Paz et al., 2007; Hodda et al., 2008), and doubtful re-isolation, resulting from changed morphology or other properties of the fungi, have been reported (Srivastava et al., 2012). Also, trees often respond negatively to endophyte colonization (Mayerhofer et al., 2013), which may affect future re-isolation success. The reliability of the present results was, however, assured as far as possible by comparisons with the non-inoculated controls, which had the same non-sterile conditions.

The purpose of using a soil-based medium, amended only with a moderate amount of fertilizer, was to create the most natural conditions and to avoid decrease in root biomass caused by acidic moss peat (an alternative medium) or damage of roots caused by over-fertilization (Mayerhofer et al., 2013).

Type of inoculum can greatly influence the effect of inoculation on plant response. Using soil as the inoculum carrier may produce different plant-fungus interactions. Abiotic soil factors can affect the chemical composition of plants (Hol et al., 2003; Joosten et al., 2009), which can subsequently affect the growth of individual fungi and composition of the fungal community in soil (Hol \& van Veen, 2002; Kowalchuk et al., 2006). Additionally, co-occurring plants can change the abiotic and biotic conditions in the soil, which can then feed back to the focal plant (Aerts \& Chapin, 2000; Klironomos, 2003; van de Voorde et al., 2011). Van de Voorde et al. (2012) found that plant biomass was greatest in pots inoculated with a 
microbial suspension and smallest in pots inoculated with soil containing the same microorganisms. We used pure cultures of single species (colonies grown on the surface of broth) and its metabolites (in the broth itself) to eliminate the added-soil effect and induce any metabolite effect.

Since the number of replicate plants treated in the inoculation tests was small (four), this study should be considered as a preliminary attempt to clarify the plant-fungus relationships. Further detailed experimentation on the effects of root fungi on the growth of oak seedlings is planned.

\section{Conclusions}

Growth inhibitors of oak seedlings were more frequent than growth stimulants among fungi isolated from roots of 80-96-year-old Q. robur growing in Wołów Forest District, where the trees had been subjected to flooding and showed symptoms of decline, suggesting that the root fungal community may contribute to oak decline.

\section{Acknowledgements}

This research formed part of a project supported by the Polish Ministry of Science and Higher Education (N303 077 31/2642 and N309 712 140).

\section{References}

Aerts R, Chapin FS (2000) The mineral nutrition of wild plants revisited: a reevaluation of processes and patterns. Advances in Ecological Research 30:1-67.

Alberton O, Kuyper TW \& Summerbell RC (2010) Dark septate root endophytic increase growth of Scots pine seedlings under elevated $\mathrm{CO}_{2}$ through enhanced nitrogen use efficiency. Plant and Soil 328: 459-470.

Anderson NA \& Anderson GW (1964) White pine root rot at the Chittenden nursery. Lake States Forest Experiment Station, U.S. Department of Agriculture, Research Note LS-26J.

Baltruschat H, Fodor J, Harrach BD, Niemczyk E, Barna B, Gullner G, Janeczko A, Kogel KH, Schäfer P, Schwarczinger I, Zuccaro A \& Skoczowski A (2008) Salt tolerance of barley induced by the root endophyte Piriformospora indica is associated with a strong increase in antioxidants. New Phytologist 80: 501-510.

Barrett LG, Kniskern JM, Bodenhausen N, Zhang W \& Bergelson J (2009) Continua of specificity and virulence in plant host-pathogen interactions: causes and consequences. New Phytologist 183: 513-529.

Carroll GC (1986) The biology of endophytism in plants with particular reference to woody perennials. Microbiology of the phyllosphere. (ed by NJ.Fokkema \& J Van den Heuvel) Cambridge University Press, Cambridge, pp. 205-222.

Clay K \& Schardl C (2002) Evolutionary origins and ecological consequences of endophyte symbiosis with grasses. The American Naturalist 160: 99127.

Contreras-Cornejo HA, Macias-Rodriguez L, Cortes-Penagos C \& Lopez-Bucio J. (2009) Trichoderma virens, a plant beneficial fungus, enhances biomass production and promotes lateral root growth through an auxin-dependent mechanism in Arabidopsis. Plant Physiology 149: 1579-1592.

Das A, Kamal S, Shakil NA, Sherameti I, Oelmüller R, Dua M, Tuteja N, Johri AK \& Varma A (2012) The root endophyte fungus Piriformospora indica leads to early flowering, higher biomass and altered secondary metabolites of the medicinal plant, Coleus forskohlii. Plant Signaling and Behavior 7(1): 103-112.

Faeth SH (2002) Are endophytic fungi defensive plant mutualists? Oikos 98(1): 25-36.

Faeth SH (2009) Asexual fungal symbionts alter reproductive allocation and herbivory over time in their native perennial grass hosts. The American Naturalist 173 (5): 554-565.

Faeth SH \& Sullivan TJ (2003) Mutualistic asexual endophytes in a native grass are usually parasitic. The American Naturalist 161:310-325.

Freeman S \& Rodriguez RJ (1993) Genetic conversion of a fungal plant pathogen to a nonpathogenic, endophytic mutualist. Science 260:75-78.

Grünig CR, Queloz V, Sieber TN \& Holdenrieder O (2008) Dark septate endophytes (DSE) of the Phialocephala fortinii s.l. - Acephala applanata species complex in tree roots: classification, population biology, and ecology. Botany 86: 1355-1369.

Halmschlager E \& Kowalski T (2004) The mycobiota in non-mycorrhizal roots of healthy and declining oaks. Canadian Journal of Botany 82(10): 1446-1458.

Hanada RE, Pomella AW, Costa HS, Bezerra JL, Loguercio LL \& Pereira JO (2010) Endophytic fungal diversity in Theobroma cacao (cacao) and $T$. grandiflorum (cupuaçu) trees and their potential for growth promotion and biocontrol of black-pod disease. Fungal Biology 114: 901-910.

Hodda M, Smith D, Smith I, Nambiar L, \& Pascoe I (2008). Incursion management in the face of multiple uncertainties: A case study of an unidentified nematode associated with dying pines near Melbourne, Australia. Pine Wilt Disease: A 
Worldwide Threat to Forest Ecosystems, Mota MM \& Vieira P (eds), Springer. pp. 15-40.

Hoeksema JD, Chaudhary VB, Gehring CA, Johnson NC, Karst J, Koide RT, Pringle A, Zabinski C, Bever JD, Moore JC, Wilson GWT, Klironomos JN \& Umbanhowar J (2010) A meta-analysis of context-dependency in plant response to inoculation with mycorrhizal fungi. Ecology Letters 13(3): 394-407.

Hol WHG, Van Veen JA (2002) Pyrrolizidine alkaloids from Senecio jacobaea affect fungal growth. Journal of Chemical Ecology 28: 1763-1772.

Hol WHG, Vrieling K \& van Veen JA (2003) Nutrients decrease pyrrolizidine alkaloid concentrations in Senecio jacobaea. New Phytologist 158: 175-181.

Johnson NC, Graham JH \& Smith FA (1997) Functioning of mycorrhizal associations along the mutualism parasitism continuum. New Phytologist 135: 575-586.

Joosten L, Mulder PPJ, Klinkhamer PGL, \& van Veen JA (2009) Soil-borne microorganisms and soiltype affect pyrrolizidine alkaloids in Jacobaea vulgaris Plant and Soil 325:133-143.

Jumpponen A, Mattson KG \& Trappe JM (1998) Mycorrhizal functioning of Phialocephala fortinii with Pinus contorta on glacier forefront soil: interactions with soil nitrogen and organic matter. Mycorrhiza 7: 261-265.

Jumpponen A \& Trappe JM (1998) Dark septate endophytes: a review of facultative biotrophic root colonizing fungi. New Phytologist 140(2): 295310.

Karst J, Jones MD \& Turkington R (2009) Ectomycorrhizal colonization and intraspecific variation in growth responses of lodgepole pine. Plant Ecology 200: 161-165.

Kessler W (1988) Root rot in young plants of oak and beech caused by Cylindrocarpon destructans. Sozialistische Forstwirtschaft 38(4): 110-111.

Klironomos JN (2003) Variation in plant response to native and exotic arbuscular mycorrhizal fungi. Ecology 84: 2292-2301.

Koch AM, Croll D \& Sanders IR (2006) Genetic variability in a population of arbuscular mycorrhizal fungi causes variation in plant growth. Ecology Letters 9: 103-110.

Kowalchuk GA, Hol WHG, \& van Veen JA (2006) Rhizosphere fungal communities are influenced by Senecio jacobaea pyrrolizidine alkaloid content and composition. Soil Biology and Biochemistry 38:2852-2859.

Kwaśna H, Szewczyk W \& Behnke-Borowczyk J (2016) Fungal root endophytes of Quercus robur subjected to flooding. Forest Pathology 46:35-46.
Larimer AL, Bever JD \& Clay K (2010) The interactive effects of plant microbial symbionts: a review and meta analysis. Symbiosis 51:139-148.

Liarzi O \& Ezra D (2014) Endophyte-mediated biocontrol of herbaceous and non-herbaceous plants. Advances in Endophytic Research (ed by VC Verma \& AC Gange) Springer, pp. 335-369.

Macia'-Vicente JG, Jansson HB, Mendgen K \& Lopez-Llorca LV (2008 a) Colonization of barley roots by endophytic fungi and their reduction of take-all caused by Gaeumannomyces graminis var. tritici. Canadian Journal of Microbiology 54(8): 600-609.

Macia'-Vicente JG, Jansson HB, Samir K, Abdullah SK, Descals E, Salinas J \& Lopez-Llorca LV (2008 b) Fungal root endophytes from natural vegetation in Mediterranean environments with special reference to Fusarium spp. FEMS Microbiological Ecology 64: 90-105.

Mandyam KG, Fox C \& Jumpponen A (2012) Septate endophyte colonization and host responses of grasses and forbs native to a tallgrass prairie. Mycorrhiza 22: 109-119.

Mandyam K \& Jumpponen A (2005) Seeking the elusive function of the root-colonising dark septate endophytic fungi. Studies in Mycology 53: 173189.

Mandyam KG., Roe J \& Jumpponen A (2013) Arabidopsis thaliana model system reveals a continuum of responses to root endophyte colonization. Fungal Biology 117(4): 250-60.

Mayerhofer MS, Kernaghan G \& Harper KA (2013) The effects of fungal root endophytes on plant growth: a meta-analysis. Mycorrhiza 23(2): 119128.

Melin E (1922) On the mycorrhizas of Pinus silvestris L. and Picea abies Karst: a preliminary note. Journal of Ecology 9: 254-257.

Munkvold L, Kjøller R, Vestberg M, Rosendahl S \& Jakobsen I (2004) High functional diversity within species of arbuscular mycorrhizal fungi. New Phytologist 164: 357-364.

Newsham KK (1994) First record of intracellular sporulation by a coelomycete fungus. Mycological Research 98: 1390-1392.

Newsham KK (2011) A meta-analysis of plant responses to dark septate root endophytes. New Phytologist 190: 783-793.

Paz Z, Burdman S, Gerson U \& Sztejnberg A (2007) Antagonistic effects of the endophytic fungus Meira geulakonigii on the citrus rust mite Phyllocoptruta oleivora. Journal of Applied Microbiology 103 (6): 2570-2579.

Piculell BJ, Hoeksema JD \& Thompson JN (2008) Interactions of biotic and abiotic environmental factors in an ectomycorrhizal symbiosis, and the 
potential for selection mosaics. BMC Biology 6: 23.

Redman RS, Dunigan DD \& Rodriguez RJ (2001) Fungal symbiosis from mutualism to parasitism: who controls the outcome, host or invader? New Phytologist 151: 705-716.

Reininger V, Grünig CR \& Sieber TN (2012) Host species and strain combination determine growth reduction of spruce and birch seedlings colonized by root-associated dark septate endophytes. Environmental Microbiology 14: 1064-1076.

Reininger V \& Sieber TN (2012) Mycorrhiza reduces adverse effects of dark septate endophytes (DSE) on growth of Conifers. Plos one. DOI: 10.1371/ journal.pone. 0042865

Richard C \& Fortin A (1974) Distribution géographique, écologie, physiologie, pathogenicité et sporulation du Mycelium radicis atrovirens. Phytoprotection 55: 67-88.

Richard C, Fortin J-A \& Fortin A (1971) Protective effect of an ectomycorrhizal fungus against the root pathogen Mycelium radicis atrovirens. Canadian Journal of Forest Research 1: 246-251.

Ridge EH \& Rovira AD (1971) Phosphatase activity of intact young wheat roots under sterile and non-sterile conditions. New Phytologist 70: 1017-1026.

Robin C \& Desprez-Loustau M-L (1998) Testing variability in pathogenicity of Phytophthora cinnamomi. European Journal of Plant Pathology 104: 465-475.

Rodriguez RJ, Freeman DC, McArthur ED, Kim JO \& Redman RS (2009 a) Symbiotic regulation of plant growth, development and reproduction. Communicative and Integrative Biology 2(2): 141-143.

Rodriguez RJ \& Redman R (2008) More than 400 million years of evolution and some plants still can't make it on their own: Plant stress tolerance via fungal symbiosis. Journal of Experimental Botany 59: 1109-1114.

Rodriguez RJ, Redman RS \& Henson JM (2004) The role of fungal symbioses in the adaptation of plants to high stress environments. Mitigation and Adaptation Strategies for Global Change 9: 261-272.

Rodriguez RJ, Redman RS \& Henson JM (2005) Symbiotic lifestyle expression by fungal endophytes and the adaptation of plants to stress: Unravelling the complexities of intimacy. The fungal community: its organization and role in the ecosystem, Dighton J, White JF \& Oudemans P(eds) 3rd Ed. CRC Press, Boca Raton, FL, USA, pp. 683-695.

Rodriguez RJ, White JF, Jr Arnold AE \& Redman RS (2009 b) Fungal endophytes: diversity and functional roles. New Phytologist 182: 314-330.
Rowe HC \& Kliebenstein DJ (2010) All mold is not alike: the importance of intraspecific diversity in necrotrophic plant pathogens. PLoS Pathog 6: e1000759.

Ruotsalainen AL \& Kytöviita M-M (2004) Mycorrhiza does not alter low temperature impact on Gnaphalium norvegicum. Oecologia 140: 226-233.

Saikkonen K, Faeth SH, Helander M \& Sullivan TJ (1998) Fungal endophytes: a continuum of interactions with host plants. Annual Review of Ecology and Systematics 29: 319-343.

Sánchez ME, Lora F \& Trapero A (2002) First report of Cylindrocarpon destructans as a root pathogen of Mediterranean Quercus species in Spain. Plant Diseases 86(6): 693.

Scervino JM, Gottlieb A, SIlvani VA, Pérgola M, Fernández L \& Godeas AM (2009) Exudates of dark septate endophyte (DSE) modulate the development of the arbuscular mycorrhizal fungus (AMF) Gigaspora rosea. Soil Biology and Biochemistry 41: 1753-1756.

Schulz B \& Boyle C (2005) The endophytic continuum. Mycological Research 109: 661-686.

Schulz B, Rommert AK, Dammann U, Aust HJ \& Strack D (1999) The endophyte-host interaction: a balanced antagonism? Mycological Research 10: 1275-1283.

Schwartz MW \& Hoeksema JD (1998) Specialization and resource trade: biological markets as a model of mutualisms. Ecology 79: 1029-1038.

Sieber TN (2002) Fungal root endophytes. The hidden half. Plant Roots (ed by Y Waisel A, Eshel \& U Kafkafi) 1st Ed. Marcel Dekker, New York, USA, pp. 887-917.

Sieber TN (2007) Endophytic fungi in forest trees: are they mutualists? Fungal Biology Rev 21: 7589.

Sinclair JB \& Cerkauskas RF (1997) Latent infection vs. endophytic colonization by fungi. Endophytic Fungi in Grasses and Woody Plants (ed by SC Redlin \& LM Carris) APS Press, St. Paul, MN, USA, pp. 3-30.

Srivastava PK, Shenoy BD, Gupta M, Vaish A, Mannan S, Singh N, Tewari SK \& Tripathi RD (2012) Stimulatory effects of arsenic-tolerant soil fungi on plant growth promotion and soil properties. Microbes Environment 27(4): 477-482.

Stoyke G \& Currah RS (1993) Resynthesis in pure culture of a common sub-alpine fungus-root association using Phialocephala fortinii and Menziesia ferruginea (Ericaceae). Arctic and Alpine Research 25: 189-193.

Sturz AV \&Nowak J (2000) Endophytic communities of rhizobacteria and the strategies required to create yield enhancing associations with crops. Applied Soil Ecology 15: 183-190. 
Sylvia D, Fuhrmann J, Hartel P \& Zuberer D (2005) Principles and applications of soil microbiology. Pearson Education Inc. New Jersey.

Tanaka A, Christensen MJ, Takemoto D, Park P \& Scott B (2006) Reactive oxygen species play a role in regulating a fungus-perennial ryegrass mutualistic interaction. The Plant Cell 18: 1052-1066.

Tellenbach C, Grunig CR \& Sieber TN (2011) Negative effects on survival and performance of Norway spruce seedlings colonized by dark septate root endophytes are primarily isolate-dependent. Environmental Microbiology 13: 2508-2517.

Tsuneda A, Wang W, Tsuneda I \& Currah RS (2009) Endomembrane system of aspen root cells plays a key role in defense against a common fungal root endophyte, Cryptosporiopsis radicicola. Mycologia 101(2): 182-189.

Tudzynski B \& Sharon A (2002) Biosynthesis, biological role and application of fungal hormones. The mycota X: Industrial applications (ed by HD Osiewacz) Springer, Berlin Heidelberg New York, 183-211.

Upson R, Read DJ \& Newsham KK (2009) Nitrogen form influences the response of Deschampsia antarctica to dark septate root endophytes. Mycorrhiza 20:1-11.

van de Voorde TFJ, van der Putten WH \& Bezemer TM (2011) Intra- and interspecific plant-soil interactions, soil legacies and priority effects dur- ing old-field succession. Journal of Ecology 99: 945-953.

van de Voorde TFJ, Van der Putten WH \& Bezemer TM (2012) Soil inoculation method determines the strength of plant-soil interactions. Soil Biology and Biochemistry 55: 1-6.

Waller F, Achatz B, Baltruschat H, Fodor J, Becker K, Fischer M, Heier T, Hückelhoven R, Neumann C, von Wettstein D, Franken \&, Kogel KH (2005) The endophytic fungus Piriformospora indica reprograms barley to salt-stress tolerance, disease resistance, and higher yield. Proceedings of the National Academy of Sciences of the United States of America 102 (38): 13386-13391.

Waller F, Mukherjee K, Deshmukh SD, Achatz B, Sharma M, Schäfer P \& Kogel KH (2008) Systemic and local modulation of plant responses by Piriformospora indica and related Sebacinales species. Journal of Plant Physiology 165 (1): 60-70.

Wang W, Tsuneda A, Gibas CF \& Currah RS (2007) Cryptosporiopsis species isolated from the roots of aspen in central Alberta: identification, morphology, and interactions with the host, in vitro. Canadian Journal of Botany 85(12): 1214-1226.

Wilcox HE \& Wang CJK (1987) Mycorrhizal and pathological associations of dematiaceous fungi in roots of 7-month-old tree seedlings. Canadian Journal of Forest Research 17(8): 884-899. 